\title{
347 - Canadian Guidelines on Alcohol \& Cannabis Use Disorders Substance Use Disorders in Older Adults
}

The United Nations $2017^{1}$ report on World Population Aging predicts that the number of persons over age 60 years will reach nearly 2.1 billion by the year 2050, representing $22 \%$ of the overall population. Despite this predicted demographic surge there is a vast lack of awareness of substance use disorders (SUDs) in older adults, a phenomenon that has been called "an invisible epidemic" by the Royal College of Psychiatrists ${ }^{2}$. Older adults, principally baby boomers, face the highest risk for SUDs ${ }^{3}$, but often go underrecognized, undertreated and underrepresented in clinical trials.

Vaccarino et al in $2018^{4}$ has put out a Call to Action to better serve the unmet needs of this population. There is an urgent need for raising awareness and improving education regarding SUDs, especially among older adults. There is also a great need for better training of health care professionals to improve their skills, knowledge, and attitudes towards treating SUDs in older adults. Policy and decision makers regarding health care delivery systems need to be better informed to make wiser decisions in order to improve access and availability of age-specific SUD treatments in older adults. To this end, The Canadian Coalition for Seniors' Mental Health (CCSMH $)^{5}$, with a grant from the Substance Use and Addictions Program (SUAP) of Health Canada, has recently created and published an introductory paper ${ }^{6}$ and a set of four guidelines on the prevention, assessment, and treatment of alcohol ${ }^{7}$, benzodiazepine ${ }^{8}$, cannabis $^{9}$, and opioid ${ }^{10}$ use disorders among older adults.

This is Part 2 of a two-part presentation of CCSMH's SUD guidelines highlighting the alcohol and cannabis use disorders in older adults; the second presentation will highlight benzodiazepines and opioid use disorder in older adults.

Authors:

Kiran Rabheru MD, CCFP, FRCP, DABPN

David K. Conn M.B., B.Ch., B.A.O., FRCPC

Peter R Butt, BA, MD, CCFP(AM), FCFP

Marilyn White-Campbell, BA Dip Grt.

Jonathan Rajeevan Bertram BSc(HON) MD CCFP(AM)

Amy J. Porath, PhD

Dallas Seitz, MD, PhD, FRCP

References:

1 The United Nations 2017 report on World Population Aging: United Nations, Department of Economic and Social Affairs, Population Division (2017). World Population Ageing 2017 - Highlights (ST/ESA/SER.A/397)

https://www.un.org/en/development/desa/population/publications/pdf/ageing/WPA2017 Highlights.pdf

2 Our Invisible Addicts, 2nd edition, The Royal College of Psychiatrists, College Report CR211

https://www.rcpsych.ac.uk/docs/default-source/improving-care/better-mh-policy/college-reports/college-reportcr211.pdf?sfvrsn=820fe4bc 2

3 Rahul Rao, Ann Roche. Substance misuse in older people Baby boomers are the population at highest risk. BMJ 2017;358:j3885 doi: 10.1136/bmj.j3885 (Published 2017 August 21)

4 Vaccarino et al 2018:

https://www.ccsa.ca/sites/default/files/2019-04/CCSA-Substance-Use-and-Aging-Report-2018-en.pdf

5 Canadian Coalition for Seniors Mental Health: https://ccsmh.ca/

6 Introduction to the Canadian Coalition for Seniors' Mental Health (CCSMH) Guidelines on Substance Use

Disorders Among Older Adults 